\title{
Using EUNIS habitat classification for benthic mapping in European seas: Present concerns and future needs
}

\author{
Ibon Galparsoro ${ }^{\mathrm{a}, *}$, David W. Connor ${ }^{\mathrm{b}}$, Ángel Borja ${ }^{\mathrm{a}}$, Annabelle Aish ${ }^{\mathrm{c}}$, Patricia Amorim ${ }^{\mathrm{d}}$, \\ Touria Bajjouk ${ }^{\mathrm{e}}$, Caroline Chambers ${ }^{\mathrm{f}}$, Roger Coggan ${ }^{\mathrm{g}}$, Guillaume Dirberg ${ }^{\mathrm{c}}$, Helen Ellwood ${ }^{\mathrm{h}}$, \\ Douglas Evans', Kathleen L. Goodin ${ }^{j}$, Anthony Grehan ${ }^{k}$, Jannica Haldin', Kerry Howell ${ }^{\mathrm{m}}$, \\ Chris Jenkins ${ }^{h}$, Noëmie Michez ${ }^{c}$, Giulia Mo ${ }^{n}$, Pål Buhl-Mortensen ${ }^{\circ}$, Bryony Pearce ${ }^{p}$, Jacques Populus ${ }^{e}$, \\ Maria Salomidi ${ }^{q}$, Francisco Sánchez ${ }^{r}$, Alberto Serranor ${ }^{r}$, Emily Shumchenia ${ }^{s}$, Fernando Tempera ${ }^{d}$, \\ Mickaël Vasquez
}

\footnotetext{
${ }^{a}$ AZTI-Tecnalia, Marine Research Division, Herrera Kaia, Portualdea z/g, 20110 Pasaia, Spain

b European Commission, DG Environment, Unit D.2 Marine Environment and Water Industries, Avenue de Beaulieu 9, 1160 Brussels, Belgium

${ }^{c}$ Service du Patrimoine Naturel, Muséum National d'Histoire Naturelle, 36 rue Geoffroy Saint-Hilaire, CP 41, 75231 Paris Cedex 05, France

d University of Azores, Department of Oceanography and Fisheries, Rua Prof. Dr. Frederico Machado, 9901-862 Horta, Portugal

e DYNECO/Applications Géomatiques IFREMER, BP 70, 29280 Plouzane, France

${ }^{f}$ Marine Ecological Surveys Ltd., 3 Palace Yard Mews, Bath, BA1 2NH, UK

${ }^{g}$ Centre for Environment Fisheries and Aquaculture Science, Pakefield Road, Lowestoft, NR33 OHT, UK

$\mathrm{h}$ Joint Nature Conservation Committee, Monkstone House, Peterborough, PE1 1JY, UK

i European Topic Centre on Biological Diversity, France

j NatureServe, Arlington, VA 22203, USA

${ }^{\mathrm{k}}$ National University of Ireland, Galway, Ireland

'Baltic Marine Environment Protection Commission (HELCOM), Katajanokanlaituri 6B, FI-00160 Helsinki, Finland

${ }^{m}$ Marine Biology and Ecology Research Centre, The Marine Institute at Plymouth University, School of Marine Science and Engineering, Drakes Circus, Plymouth, PL4 8AA, UK

${ }^{n}$ ISPRA, Via Viataliano Brancati 60, 00144 Rome, Italy

${ }^{\circ}$ Benthic Habitat and Shellfish Institute of Marine Research, Bergen, Norway

${ }^{\mathrm{p}}$ Gardline Caledonia Ltd., Marine Ecological Surveys Ltd., 69 Buchanan Street, Glasgow, G1 3HL, UK

q Hellenic Center for Marine Research (HCMR), Institute of Oceanography, 46.7 km Athens-Sounio, 19013 Anavyssos, Greece

${ }^{r}$ Instituto Español de Oceanografía, Centro Oceanográfico de Santander, Spain

${ }^{s}$ Graduate School of Oceanography, University of Rhode Island, Narragansett, RI 02882, USA
}

*: Corresponding author : Ibon Galparsoro, Tel.: +34 667174450 ; email address : igalparsoro@azti.es

\section{Abstract:}

The EUNIS (European Union Nature Information System) habitat classification system aims to provide a common European reference set of habitat types within a hierarchical classification, and to cover all terrestrial, freshwater and marine habitats of Europe. The classification facilitates reporting of habitat data in a comparable manner, for use in nature conservation (e.g. inventories, monitoring and assessments), habitat mapping and environmental management. For the marine environment the importance of a univocal habitat classification system is confirmed by the fact that many European 
initiatives, aimed at marine mapping, assessment and reporting, are increasingly using EUNIS habitat categories and respective codes. For this reason substantial efforts have been made to include information on marine benthic habitats from different regions, aiming to provide a comprehensive geographical coverage of European seas. However, there still remain many concerns on its applicability as only a small fraction of Europe's seas are fully mapped and increasing knowledge and application raise further issues to be resolved.

This paper presents an overview of the main discussion and conclusions of a workshop, organised by the MeshAtlantic project, focusing upon the experience in using the EUNIS habitats classification across different countries and seas, together with case studies. The aims of the meeting were to: (i) bring together scientists with experience in the use of the EUNIS marine classification and representatives from the European Environment Agency (EEA); (ii) agree on enhancements to EUNIS that ensure an improved representation of the European marine habitats; and (iii) establish practices that make marine habitat maps produced by scientists more consistent with the needs of managers and decision-makers. During the workshop challenges for the future development of EUNIS were identified, which have been classified into five categories: (1) structure and hierarchy; (2) biology; (3) terminology; (4) mapping; and (5) future development. The workshop ended with a declaration from the attendees, with recommendations to the EEA and European Topic Centre on Biological Diversity, to take into account the outputs of the workshop, which identify weaknesses in the current classification and include proposals for its modification, and to devise a process to further develop the marine component of the EUNIS habitat classification.

Keywords: Habitat classification scheme ; EUNIS ; Marine habitats ; Habitat mapping 


\section{Introduction}

The European Union Nature Information System (EUNIS) habitat classification aims to provide a common European reference set of habitat types, within a hierarchical classification to allow the reporting of habitat data in a comparable manner for use in nature conservation (e.g. inventories, monitoring and assessments) (Davies \& Moss, 2002). The classification is intended to (i) provide a common and easily understood language for the description of all marine, freshwater and terrestrial habitats throughout Europe (but not intended to supplant existing national or sectoral systems); (ii) be objective and scientifically based, with clear definitions and principles; (iii) hold information in a relational database allowing interrogation based on a number of parameters; (iv) seek as far as possible to achieve a consensus amongst those concerned with habitat classification as developers or users; $(\mathrm{v})$ be comprehensive, but applicable at a number of hierarchical levels of complexity in recognition of the variety of its applications; and (vi) be flexible so as to evolve and allow the admission of new information, but also sufficiently stable to support users of its predecessors and other systems.

The importance of a univocal habitat classification system is confirmed by the fact that a number of European policies, including the Habitats Directive (92/43/EEC), the Marine Strategy Framework Directive (MSFD; 2008/56/EC), the Infrastructure for Spatial Information in the European Community (INSPIRE; 2007/2/EC), and the Maritime Spatial Planning (MSP) roadmap (European Commission, 2008), aimed at marine mapping, assessment and reporting are increasingly using EUNIS habitat categories and respective codes so as to guarantee a common shared path and technical terminology between Member States. Specifically, in terms of the implementation of the MSFD, habitat maps are being used at various steps; starting from the qualitative descriptors for determining good environmental status (e.g. biological diversity and seafloor integrity) and as indicative lists of characteristics, pressures and impacts (e.g. predominant habitat types, identification and mapping of special habitat types, biological features) (see Borja et al. (2010)).

EUNIS classification is organized into hierarchical levels (Figure 1) (Davies et al., 2004) (EUNIS habitat type hierarchical view is available at http://eunis.eea.europa.eu/habitats-code-browser.jsp). Initially, it was developed to level 3 for terrestrial habitats and level 4 for marine ones. The present version of the classification starts at level 1, where 'Marine habitats' are defined, up to level 6 . The marine section of EUNIS was initially based on the Marine Habitat Classification for Britain and Ireland, which was most developed in coastal regions where the majority of the available data was found (Connor et al., 2004). Since the launch of this information system, substantial efforts have been made to expanded and incorporate existing classifications for the Baltic and Mediterranean and newly-developed classifications for pelagic habitats and the deep-sea, thereby advancing the system"s comprehensiveness in terms of its geographical coverage of European seas (Davies et al., 2004). 


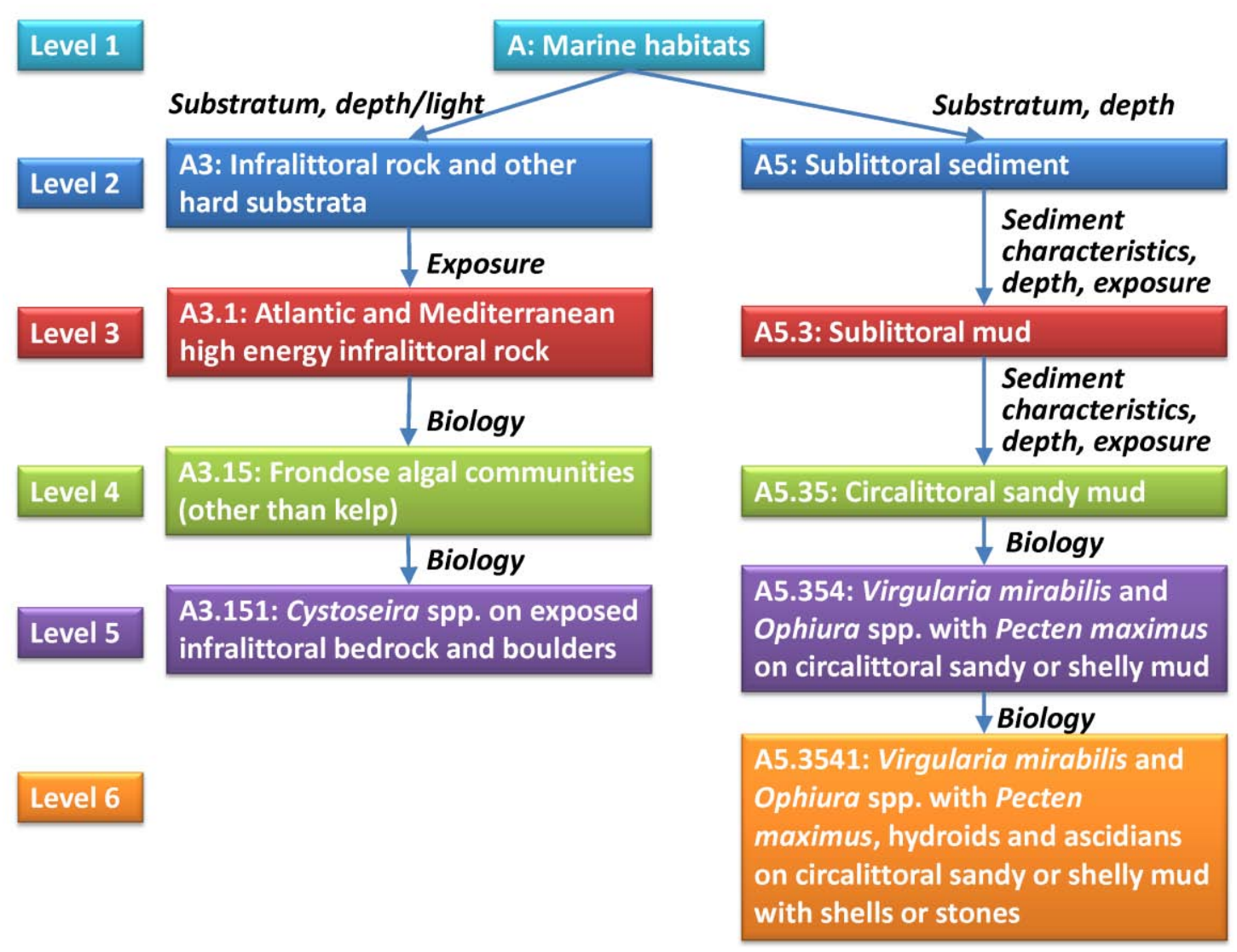

Figure 1. Two examples of the EUNIS hierarchy and the main criteria used at each level of the classification. The example on the left is a rocky environment and the right illustrates sedimentary environment habitats. It should be highlighted that biological data are required to reach to level 4 for rocky habitats; meanwhile, community information is required at level 5 for sedimentary habitats classification.

Since 2004, it has been recognised that some regional seas were poorly represented; for example, the Baltic Sea. Thus, the recent updates to EUNIS (now version 2007.11) have included some Mediterranean and Black Seas specific biotopes at levels 4, 5 and 6 . And, on the other hand, there is increasing recognition that the deep-sea section (A6) of the classification system was not adequately addressing the variation in seabed habitats beyond $200 \mathrm{~m}$ below sea-level (Howell, 2010).

Despite the aforementioned drawbacks, the EUNIS classification has been used both for. direct mapping of observed habitats and for habitat modeling, to produce predictive maps of habitat distribution for both research and practical applications; e.g. Coggan \& Diesing (2011), Diesing et al., (2009), Guarinello et al., (2010), Howell, (2010), Salomidi et al., (2012). For example, the Council of Europe is now using the classification as the basis of its Resolution 4 on a list of habitats to be protected by the Emerald network of sites (Council of Europe, 2010). The classification has also been used by various marine mapping projects such as BALANCE, EUSeaMap and MESH (Al-Hamdani \& Reker, 2007; Cameron \& Askew, 2011; Coltman et al., 2008) which have developed predictive habitat maps based on EUNIS-compatible habitat classes for large areas of European seas. These types of project strongly depend on having an agreed seabed habitat classification that ensures consistency and harmonization in mapped outputs throughout the project areas. The International Council for the Exploration of the Seas (ICES) working group on marine habitat mapping (ICES, 2011) has also been instrumental in promoting EUNIS, as illustrated by the ICES data centre webGIS which offers a discovery site for habitat maps over the North Atlantic area, 
listing many EUNIS-based habitat maps (http://geo.ices.dk/viewer.php?add_ layers=ices_eg:wgmhm_surveyed_habitat_maps).

While the specific projects mentioned above, and many others, have greatly increased our knowledge of the marine environment, they have also revealed a number of problems with the current version of the marine section of the EUNIS classification. One consequence of this is that, at a national level, there are many examples where habitat mapping studies have found difficulty in assigning their observations to the classes that currently exist in the EUNIS system.

As mentioned above, the current version of the EUNIS classification dates from 2004 (Davies et al., 2004) with only relatively minor changes since then. The lack of revision since then has provided a period of stability for users but it has become increasingly evident that further development and revision is now necessary. Due to this situation, a meeting was held at the European Environmental Agency (EEA) in October 2011 to discuss both the types of revision required and the future governance of the classification. A paper on a proposed governance structure will be submitted to the EEA in 2012, which will establish a mechanism for evaluating proposals from users and for more strategic evaluations of required developments (D. Evans, pers. comm.).

In response to the situation noted above, and in the light of new habitat mapping initiatives and European directive implementation requirements, a workshop entitled "Using EUNIS habitat classification for benthic mapping in European seas" was organized by AZTI-Tecnalia in San Sebastian (Spain) on $23^{\text {rd }}-24^{\text {th }}$ April 2012 within the framework of the Interreg project MeshAtlantic. The event was focused upon the interchange of scientific knowledge gained in different marine habitat (mapping) programmes around European regions including the Baltic, Atlantic, Mediterranean and North Sea, using the EUNIS habitat classification, together with the experience of scientists using other habitat classification schemes in Norway and the USA. The objective of the meeting was to share experience of different research teams in the current use of the classification, and their perspectives on adaptation and development of the EUNIS classification scheme for present and future needs. Hence, the specific objectives of the workshop were to: (i) bring together scientists with experience in the use of the EUNIS classification, and representatives from the EEA; (ii) agree on enhancements to EUNIS that would ensure an improved representation of European marine habitats; and (iii) establish practices that make marine habitats maps produced by scientists more consistent with the needs of managers and decision-makers. This review summarizes the main results and agreements obtained during this workshop.

\section{Findings and discussion from the workshop}

The workshop was attended by 95 people from 10 countries. Fifty-two institutions were represented including the European Commission (Directorate General Environment), European Topic Centre on Biological Diversity (ETC-BD), Helsinki Commission (HELCOM), national governments, research institutes, universities, private companies, Non-Governmental Organizations (NGOs) and students. During the two-day workshop, 24 oral presentations and 12 posters were presented. Extended abstracts were summarized into a public access Proceedings Book (Galparsoro, 2012). The presentations tackled experiences of case studies from France, Greece, HELCOM countries, Ireland, Italy, Norway, Portugal (including Azores), Spain, UK and USA. Hence, the presentations covered experience from different biogeographic areas, including the Baltic Sea, North-east and North-west Atlantic, Macaronesia, North Sea and Mediterranean Sea. 
Concerns on advantages and disadvantages of using of EUNIS classification were expressed by the delegates and potential solutions were discussed. In many cases, the aforementioned concerns were common to many scientists, and thus, they have been categorized into five topics that are summarized below.

\subsection{Structure and hierarchy}

The need for structural changes in the upper levels of EUNIS was one of the common points in most of the presentations:

For littoral habitats, supralittoral habitats types are listed both under marine habitat (class A) and under coastal habitats (class B) in the first level of the classification. To avoid duplication, the supralittoral types should be assigned to either one or the other part of the EUNIS classification, not to both.

Another concern rose for purely marine and estuarine habitats. The discussion focused on whether or not it would be better to introduce estuarine habitats as a distinct class at a higher level in the hierarchy. The justification for the current system is that for rocky habitats and sediment habitats, the biotic communities are regarded as a local variant (impoverished version) of the fully marine type, and so only warrants discrimination at the lower hierarchical levels (5/6). However, when habitat modeling approaches are used, it is possible to identify estuarine areas quite easily, so it may be desirable to distinguish these habitat types at the higher levels of the classification, as it is these higher levels that are most commonly used to inform decisions relating to policy and marine spatial planning. The problem with this point is that if the aim of the EUNIS classification is to be biologically meaningful it should aim as far as possible to keep similar communities together within the structure of the classification, but organizing the classes according to physical parameters might result in similar communities being located in different parts of the classification.

In the present version of EUNIS, habitat classes are not always equivalent at a particular level in the classification. The marine section of the EUNIS classification uses substratum, energy (exposure to wave action and currents) and biological zone to characterise physical habitat types, but it introduces these factors at inconsistent levels in the hierarchy. Rock and sediment substrata are differentiated at EUNIS level 2; however, the scheme introduces the littoral, infralittoral and circalittoral biological zones at level 2 for rock habitats, but only at level 4 for sediment habitats and, thus, it may not represent equivalence in their biological character. The outcome of this is that a level 3 EUNIS map will discriminate biological zones for rock habitats but not for sediment habitats. This causes internal inconsistencies in maps classified at EUNIS level 3. The consequence of this mismatch in the classification is that some parts of a map will show the biological zones whilst others will not. For example, a level 3 map can show potential kelp habitat on rock but cannot show potential Zostera habitat on sand, yet both are in the infralittoral zone. Accordingly, it is recommended that specific hierarchical levels of the classification should include the same specific type of information. Thus, changes at level 2 are recommended to accommodate distinct subdivision of hard and soft bottom communities for all biological zones (as defined for example in benthic Mediterranean manuals). This would allow adequate differentiation of soft-bottom communities of the infralittoral and circalittoral zones and, it would permit the accommodation of new emergent deep-sea soft bottom habitats.

Another highlighted concern was that the deep-circalittoral zone (i.e. below the wavebase) is introduced for sediment habitats at level 4, but is never formally introduced for rock habitats; instead some level 4 rock habitats include "deep" in their title. With the current structure of EUNIS, the only way to represent the biological zones equitably 
within a single map is to classify rock habitats to level 3 and sediment habitats to level 4. Also, in order to be complete, and a new class has to be made at level 3 for deep circalittoral rock.

Several speakers suggested that the parts of the classification dealing with the deepsea $(>200 \mathrm{~m}$ ) needs to be reorganized and further developed. The present version of EUNIS shows just one class at level 2 for deep-sea habitats while there are four classes at level 2 for ,shallow seas" (i.e. on the continental shelf). It was argued that new data have demonstrated the existence of much variety in benthic deep-sea habitats and thus EUNIS needs a better balance to represent this realm. Several possible sources for advancement in this area have been suggested recently. The Joint Nature Conservation Committee (JNCC) is proposing changes to the deep-sea sections in its own UK-based "Marine habitat classification for Britain and Ireland" (Connor et al., 2004) but is also working towards integration with the wider European community and the current EUNIS classification system.

Other topics regarding to the hierarchy of the classification were also discussed. Those aspects are summarized below.

\subsubsection{Biogeography}

It was discussed whether the biogeography was already addressed adequately by lower level species composition of biotopes. It was suggested that broad-scale biogeographic patterns, resulting from major salinity and temperature characteristics of regional seas, should be specifically accommodated in the classification (which are at present, partly reflected by labels of Baltic, Mediterranean, and Atlantic Seas, but which needs a more consistent approach); and beside this, finer resolution biogeographical changes may be best reflected at lower levels.

Another important point is that EUNIS top level categories, being defined in a qualitative way, need to be specified by quantitative thresholds that best represent the variety of the physical environment with regard to lower biologically-defined classes stemming from them. Although several basins or sub-regions may share identical features or parameters (e.g. substrate type, seabed energy and depth zone in the Atlantic sub-regions (see McBreen et al., (2011)), their magnitude and therefore their thresholds may vary substantially between basins. This is the case for the Mediterranean where currents are typically weaker than in the Atlantic, but has a significant effect in determining habitat and benthic community ocurrence. In addition, greater account should be taken of the fact that these large marine basins have their own specific characteristics in terms of communities and biological components, and consequently there are strong reasons for introducing more biogeographical aspects to EUNIS. Additional region-specific physical drivers may be required at upper levels within EUNIS, which might become a difficulty if the current hierarchical structure is to be maintained. As an illustration of this constraint, the EUSeaMap project produced two separate maps for the Baltic Sea: one with a EUNIS-based energy dominated classification and one with an alternative salinity dominated classification that was not compatible with EUNIS, but included a physical driver that is considered to be more important in this basin.

At this point, a question arose: at what stage should biogeography be considered in the classification? And, how should these relevant habitat types be arranged into a hierarchy, e.g. at which level in the scheme should each physical variable be introduced? There are two approaches to this, and the best solution may be a combination of both: 
a) Refer to biogeographic regions only where relevant, as is the case for many Mediterranean biotopes, e.g. A5.28 Mediterranean communities of superficial muddy sands in sheltered waters, which appears below the generic A5.2 Sublittoral sand. This allows habitats formed by similar conditions to be grouped together under the same ,parent" habitat. However, there can sometimes be a risk of grouping biotopes that appear to be driven by the same environmental factors, as described in the parent habitat, when they are, in fact, driven by unrelated factors that sometimes occur together.

b) Separate biogeographic regions at the upper levels of EUNIS; which would lead to a separate classification system for each region. The risk with this solution would be the duplication of many habitats and biotopes that are equivalent but exist in other sections of the classification system. This might lead to an inability to identify similar habitats across basins. However, if a region is substantially different in terms of the main controls on the broad habitat types (e.g. salinity as is described for Baltic regions), then it may be sensible to use this approach.

Biogeography is also relevant for the deep-sea bed (below $200 \mathrm{~m}$ ) habitats of the Atlantic, Mediterranean and Black Seas. Hence, it is also worth considering that the biogeographic dissimilarities in the deep-sea are related to water properties, i.e. temperature, density, salinity etc.; e.g. in the Atlantic, the biological communities of deep-sea habitats in Arctic waters are distinct from those south of the WyvilleThompson ridge in Atlantic waters (Howell, 2010). Also, the Mediterranean deep-sea zones are relatively isolated from the Atlantic ocean as a result of the shallower depths in the Strait of Gibraltar, and it may therefore be argued that the biogeography differs so greatly in the Mediterranean that EUNIS should divide Mediterranean from Atlantic deep-sea habitats at a high level; although the Mediterranean would still retain common habitat types in the intertidal, infralittoral and circalittoral zones.

The deep-sea zones proposed by Howell (2010) are defined by depth ranges. Although, it is accepted that depth itself is not the driver for the observed changes in biology, it could be used as a proxy for less well understood properties that define the water mass structure, and subsequently, the environmental driving factors that determine the distribution and characteristics of benthic habitats (Galparsoro et al., Submitted; Glockzin \& Zettler, 2008; Todd \& Kostylev, 2011). The oceanographic characteristics can vary greatly on a geographic scale due to the nature of deeper water, and thus impact on communities more than would be expected in shallower locations within the photic zone (Fabri et al., 2006). Ideally, taking these aspects into consideration would make EUNIS a more robust classification, but it was also agreed that the biogeographical aspect is more complex than a simple consideration of the temperature and salinity properties of the water masses; it must also be able to deal with factors such as the natural geographic range of species, recognising they will become rarer as the observer moves towards the edge of that range, and will be absent beyond it. Thus, clarity is needed on the use of the term "biogeography" in the context of habitat classification; for example, being able to differentiate between ocean characteristics (e.g. temperature, salinity) and the natural geographic range of species. It would be instructive to consider some of the recent work that has been done in the field of bioregionalisation (e.g. Spalding et al., (2007)) and marine biogeography (e.g. Briggs \& Bowen, (2012) as these may provide some guidance on biogeographical classifications that could be adopted by a revised EUNIS system .

Finally, another aspect linked to biogeographical differences across European seas was the suggestion for further development and the inclusion of new, ecologicallyrelevant habitat classes for certain structuring species (e.g. red algae habitat classes). 


\subsubsection{Substratum}

As already highlighted, the EUNIS system recognizes two main types of substrata, namely rock and sediment, so mapped areas have to be classified as either rock or sediment. However, there are significant areas of the seabed where bedrock occurs at the seabed surface in association with a thin $(<0.5 \mathrm{~m})$, often discontinuous, covering of sediment, leading to a mosaic of rock and sediment habitats (Coggan \& Diesing, 2012; Galparsoro et al., 2010). In the present version of the classification rock-sediment combinations are not dealt with adequately; the only class of relevance being A3.12: sediment affected habitat. The problem with the rock and sediment habitat classes is that the benthic community in these areas includes species characteristic of both rock and sediment habitats, so it does not match well to the current biotope descriptions. It is equally wrong to describe the area as a rock or sediment habitat, because it displays characteristics of both. Therefore, this cannot be represented using the current EUNIS classification system as it only recognizes separate rock or sediment habitats. It was suggested that the solution to this problem could be the introduction of a third substratum class called "Rock and thin Sediment", which would sit between the rock and sediment habitats. This solution has recently been proposed by James et al., (2011) (2011) and Coggan et al., (2011). However, further research is required to investigate the extent to which these habitats are mosaics of rock and sediment habitats mapped at a broad scale, or whether the small thickness of the sediments overlaying the rock leads to unique biological communities.

On the other hand, for sediment habitats, the EUNIS classification system recognizes four sediment classes at level 3 of the hierarchy, namely coarse sediments, sand, mud and mixed sediments. These have been mapped to the standard Folk trigon (Folk, 1974) to apportion the more familiar Folk sediment classes to EUNIS sediment classes (Long, 2006). Nevertheless, many of the communities listed under EUNIS "sand" biotopes are found in mixed, coarse and muddy substrata, and the original mapping of EUNIS substratum types to the Folk trigon may have restricted the EUNIS sand class to too small an area of the trigon. A revised division, expanding the sand class and reducing the gravel and mud classes to give the partitioning, was first proposed by James et al, (2010) and has subsequently been used in other studies (James et al., 2011; Tappin et al., 2011). This modification has significantly reduced the mismatch between EUNIS classes determined from grab samples and broad-scale modelled EUNIS maps. Thus, a change in boundaries of sediment classes in the trigon was suggested (Coggan et al., 2012b; Pearce et al., 2011). Sandy biotopes, which currently must be assigned to coarse sediment in EUNIS, could be shifted to sand class (alongside fine sand types) if their biology was considered more akin to sand types (i.e. change boundary of higher type). Further analysis would be necessary to test new boundaries (especially as this was tried already in UKSeaMap 2010 (McBreen et al., 2011), but with inconclusive outcomes). The proposal therefore needs testing in other regions before any modification of EUNIS as it would have a major influence on classification and any resultant maps.

Moreover, although infaunal communities can be quite distinct in their species composition (and so be considered a biotope), they rarely show fidelity to one of above mentioned four sediment classes and can typically be found in two or more of the classes (Coggan et al., 2012b). Unfortunately, the EUNIS system assigns a particular community type to one and only one sediment class, so while sediment composition of a grab sample may indicate that it should be assigned to a mixed sediment class (A5.4), its faunal composition may force that sample to be assigned to a biotope that falls under the sand class (A5.2), simply because that community type is only listed under the "sand" class of substratum in the EUNIS classification. This can cause patchiness when trying to draw EUNIS maps using just empirical data, and significant 
disagreements between EUNIS classes derived from broad-scale modelled maps and those derived from point sampling at a given location.

It was highlighted that the results obtained in new mapping initiatives (e.g. EUSeaMap project (Cameron \& Askew, 2011)) also had identified the existence of new habitat categories in the bathyal and abyssal zones previously not described in EUNIS. Those new habitat categories referred to the presence of new sediment categories, namely mixed sediments and muddy sands in the bathyal zones and mixed sediments, sand and muddy sand in the abyssal zone. Though such considerations are only based on broad-scale modeling of substratum and biological zone parameters, and no information is available on the associated biological assemblages, the modeled map clearly indicates the existence of such habitats from an abiotic point of view. This point also relates to the reduced number of habitat classes at level 2 that was highlighted previously in the "Structure and hierarchy" section.

Substrata stability, in terms of sediment dynamic processes due to wave and current induced sediment transport, was also considered as a difficult but important aspect that should also be taken into account in EUNIS. This is because the same substratum grain size can support markedly differing biology depending on whether it is mobile or stable. In the present EUNIS classification version this is partly addressed by the 'energy' classes and at level 3 for rocky/stony habitats, but it is not considered for sediments. It was suggested that substrata stability should be considered for sediment substrate, at the same classification level as for hard substrate habitats (i.e. rock).

\subsubsection{Energy / exposure}

Difficulties were highlighted during the Workshop when defining and mapping exposure classes around European regions for rocky habitat types. To a certain extent, this is due to regional perceptions of exposed and sheltered habitats that vary according to typical ranges within a region. A universal scale with more classes than at present (sheltered, moderate, exposed) may result in more accurate 'description' of local perceptions. These were suggested to be included at levels 5/6 only. This aspect also relates to the threshold definitions highlighted in the "Biogeography" section of this article.

Nevertheless, for energy classes definition, thresholds defined with field recording (oceanographic buoys and current-meters) are more finely divided for both wave and current exposure, but they are considered to be too fine for the upper levels of the EUNIS classification. A good approach to this would need to relate biological change to physical exposure through improved models (Bekkby et al., 2008; Coggan et al., 2012a) so that finer resolution information could be reflected in maps.

\subsubsection{Zonation}

It was agreed that the definition of zones must be biologically meaningful, and comparable across different regional seas and countries (Dauvin et al., 2008a). In that sense, it was suggested that another type of zonation could be applied to rock habitats (at level 3). One relevant criterion would be the zonation above and below wave disturbance, as it is a clear zonation which is reflected in the biological characteristics and ecological functioning of the habitats. The main concern with applying criteria is that this parameter also varies with region (e.g. Atlantic, Mediterranean or Baltic Sea) and the definition of thresholds. In contrast, for areas with good bathymetric information, it could be defined by the seafloor morphological features that reflect 
sedimentary processes. It was considered that the circalittoral/deep circalittoral divide is also highly relevant to the assessment and management of sediment habitats under the MSFD, as any assessment of their condition must consider the magnitude of human impacts caused by activities such as trawl fishing and marine aggregate extraction in the context of the magnitude of natural disturbance cause by waves, storms and currents.. By definition, the deep circalittoral lies below the wave base so these habitats are exposed to far less natural disturbance that infralittoral or circalittoral habitats. Consequently, the faunal communities of the deep circalittoral are not preadapted to seabed disturbance and so are likely to show far lower levels of resilience and resistance to man-made physical disturbance than the communities in the infralittoral and circalittoral which are accustomed, to some extent, to cope with moderate or even severe levels of disturbance.

As has been highlighted in the discussion on the EUNIS hierarchy (above), there is a need to improve the definitions of deep-sea zones. Such zonation should reflect 'water mass' characteristics and should therefore avoid the temptation of adopting mere depth boundaries as water masses do not adhere to these; instead, the depth at which they occur varies between different geographic regions. For example, it is observed that marked changes at $50 \mathrm{~m}, 850 \mathrm{~m}$ and $2050 \mathrm{~m}$ water depths in „facies" linked to 'ocean' zones in the Azores are $+/-200 \mathrm{~m}$ different to the equivalent zones observed in UK waters ( $F$. Tempera pers. comm.). Thus, the identification of parameters which drive these zonal changes and further work to define physical/biological boundary in different regions are needed (considering various relevant physical factors), to support the MSFD (in particular, the mapping of predominant habitat types).

The current deep-sea classification covers the upper slope to hadal depths. Environmental conditions over these depths vary greatly and the classification should be developed to better represent this heterogeneity. The biogeographic diversity within the deep-sea should be taken into account and classes should not only be defined in relation to environmental conditions but also the diversity related to the life history of regions (Howell et al., (2010). It is important to note that the present proposal of classes has been based on UK deep-sea investigations and further analysis would be required to depict depth bands in other regions. A structural change to the deep-sea classification would likely cause difficulty for future mapping exercises and some discussion will be needed to develop the best solution to minimize discontinuity between the deeper and shallower regions. This is complicated by the fact that not all environmental parameters that define coastal and shallower waters (such as light penetration and wave exposure) are applicable to deep-sea communities.

Howell et al. (2010) propose five zones defined by depth for the deep sea. This zonation has already been used in mapping exercises (UKSeaMap 2010 and EUSeaMap) and is a strong basis for better defining some of the environmental variability. The classes are:

1. Upper Slope/ Bathyal margin (name to be confirmed)

2. Upper bathyal zone

3. Mid bathyal zone

4. Lower bathyal zone

5. Abyssal zone 
The rationale behind this proposal is that depth could be considered as a surrogate for 'water masses' and for different biological communities that can be found in each of these zones. Moreover, it is generally available information which could be used at very broad scale habitat mapping. The main discussion topic is that even though depth is used throughout the classification system, it is important to understand that it is used as a proxy for other factors and, therefore, should not be assumed that different regions, at comparable depths and sediment types, display a ubiquitous environment.

However, there are other options for restructuring the deep-sea portion of the marine classification (Madden et al., 2009). Discussion will be needed on some of the more practical options with a wide consensus to be achieved. There will be positives and negatives to a restructuring exercise but a credible and effective way to classify the deep sea is necessary.

\subsubsection{Functional biology}

By definition, the most effective habitat classification would be the one that could accommodate the biological variation within 'functional habitats'. This approach needs good understanding of the ecosystem, and a move from 'description' of what is measured or seen, to the 'understanding' of the dynamics. This approach is already reflected in some regions and classifications (e.g. the use of facies/associations in the Mediterranean). It would also allow the descriptions of perturbed communities and natural communities as alternative reflections of the same functional habitat, with a direct use for management and the definition the good environmental status within the MSFD. Thus, the use of functional groups, rather than species, to recognise similar habitat types across regions is encouraged. This concept is already reflected in certain parts of classification as level 4 types (rocky circalittoral, intertidal sediments, etc.) and should be extended, with level 5 types distinguished at species level in communities.

The use of the hierarchical approach for mapping can help in producing 'management units' above the level of biotopes. The scale of habitat types represented in the map should be taken into account depending on the management purpose. Hence, criteria for hierarchy can vary - level 4 was originally designed (from UK types) as 'functional communities' with similar sensitivities to impacts.

\subsection{Biology / upper levels}

The lower, biological EUNIS levels were made on the basis of field samples (very local by essence), which, due to the hierarchical structure, had to be reconciled with abiotic data (more regional in essence) at upper levels. The latter lend themselves much better to modeling and mapping but some of the physical boundaries lack quantitative definitions, producing difficulties for habitat classification when mapping. Whilst in many cases a species or a community may have a one-to-one correspondence with any combination of environmental parameters, in many other cases there may be a one-tomany relationship. For example, circalittoral and deep-sea Lophelia pertusa reefs are located in different parts of the classification but have only minor differences, while Mytilus beds occur in estuaries, on exposed rocky shores and in the subtidal zone across the Baltic, offering dramatically different physical habitats but one dominant species. In these cases, not all physical features can be inferred from the biology, which requires the abiotic parameters to be identified separately. In an idealized EUNIS hierarchy, the biological and physical visions of the seabed should converge towards a more thorough and universal description; however, this can be difficult for "biotopes" 
that straddle major boundaries in the classification. One suggestion could be to use single dominant species to bring all subtypes under one „umbrella".

An effort should be made to improve the detail of biotope descriptions to reflect all local types (e.g. to expand geographical scope), encompass all national typologies and accommodate sub-national variation within national typologies.

The biological descriptions of the habitats should also capture information on variations to the "original habitat" and the description of "disturbed" communities with information on opportunist algae and invasive species.

During this development, metadata including the historical information on the definition of the habitat is needed. This is partly captured in EUNIS database, but there is a need for metadata with information regarding to the origin and changes to each type. This could be related to the appropriate INSPIRE directive (Council Directive 2007/2/EC, 2007) standard.

\subsection{Terminology}

Consistency in nomenclature is particularly important for a common interpretation and use of the classification. Errors come from nomenclature issues due to practice and interpretations that vary from one language and nation to another, introducing translation and transposition errors (e.g. divergence around the concept of supralittoral and the upper limit of the sublittoral). Terms such as habitat, biotope, biocoenosis, peuplement, etc., tend to merge in EUNIS as 'synonymous', when there are many differences among them (Dauvin et al., 2008a, b). Terms such as biocenose and biotope are considered synonymous by some authors; however, others described the addition of both as parts of the ecosystem. "Facies" (predominance of a particular animal species) and ,association" (predominance of a particular plant species) are defined as different "forms" of the same biocenose as opposed to different levels within a hierarchy, and can reflect human impacts. Use of variations within a biotope e.g. to reflect anthropogenic impacts, needs a consistent approach. Consistency in nomenclature is particularly important for describing reference states and ecosystem change.

The improvement of the habitat description and species composition should be done with the adoption of standard species nomenclature (link to the World Register of Marine Species (WoRMS) or European Register of Marine Species (ERMS)).

\subsection{Mapping}

A good habitat classification scheme should be suitable for use with current habitat mapping techniques and modeling approaches (Brown et al., 2011). A habitat classification scheme that could fit with the outputs of these techniques would make it more useful. From a more practical point of view, distinction of habitats compatible with the discriminatory capabilities of remote sensing techniques should be considered. For example: on subtidal rocky substratum, kelp forests and sparse kelp meadows are discriminated as a single unit using remote sensing techniques, but within EUNIS they are separatedinto multiple categories, which presents problems of classification accuracy when trying to make a map. 
Another issue highlighted was the possibility of using information derived from remote sensing techniques as proxy for definition of thresholds of certain environmental variables. For example, wave exposure for rock habitats is difficult to determine in the field and in some mapping surveys the criterion of exposure has been abandoned in favor of dominance of coverage by vegetal or animal species (for example fucoids or mussels), which is easily observable on site or via remote sensing. Hence, for certain cases, there is often a wish to use gross biology on shores (fucoids/barnacles/mussels) in preference to exposure classes as these are easier to map. Nevertheless, a drawback of using this approach is that, in some cases, the animal or vegetal coverage might be quite variable over time (years) with all three life-forms occurring in the same functional habitat (moderately exposed rocky shore) and so may not best serve certain uses of the classification (which the exposure classes do).

The use of large fauna (from video data) to describe habitat types requires, generally, a better understanding of how robust such classes might be (e.g. density of Pheromena to define a bioherm). The visual perception could result in a poor taxonomic resolution (visual identification of large fauna from video/stills), often with very few species per 'sample'. Another concern is that the sample size (still images along a video tow) may be too small in relation to the entire record. In such cases, creation of a larger sample size (e.g. a length of video of 'uniform' character) is needed to help overcome this problem.

Nevertheless, a need was highlighted for a balance between a "technology-led" approaches to categorizing and mapping habitats and the needs of management in assessing sensitivity and degree of biological change in habitats, as it is not always simple to decide which approach takes priority.

On the other hand, in mapping processes where existing habitat maps have been collated and transformed into EUNIS classes, it has been found that the conversion of old maps to EUNIS results in the loss of discrimination for some of the classes in the original maps (e.g. sedimentary substrata). This could happen as a result of old types all sitting within one current EUNIS class, which is not desirable. For example, the spatial extent of sediment types can mean a single level 5/6 type covers a large mapping area even though it is regarded as only a minor type in the classification.

\subsection{Development}

Attempting to create a single classification system based on biology across Europe has been demonstrated to be difficult. Up to a certain extent, it seems necessary to maintain the higher level physical types if a hierarchical system is to be maintained. The higher physical levels (boundaries, classes) must reflect the biological component of the habitat and need to link to functional biology in the first instance, and this means a common understanding of the lower levels. Then, the question raised is: should EUNIS be developed at all below level 4 or should detailed ,biotope" classification (the equivalent of EUNIS levels 5/6) rely on typologies relevant to the different bio-regions? The first drawback of this solution is that there is a need for consistency in typology at levels 5 and 6 if maps produced by different Member States are to be merged to produce broad-scale continuum maps for European seas. But, at the same time, too detailed biotope maps for broad geographical scale could become very difficult to represent/map and to be useful for management. One of the applications of habitat maps is the monitoring the loss of a particular biotope and triggering a management action to try to secure its recovery, which might be difficult to attempt at European level. 
Nevertheless, for certain habitats, the EUNIS classification already draws from international typologies and this should be further developed (e.g. Barcelona Convention, HELCOM, OSPAR).

\subsubsection{New habitat classes}

The necessity of including new habitat classes in the present classification was agreed by all the scientists present at the workshop. Most of the new classes to be proposed come from national habitats lists, and in most cases, could be incorporated into the present structure of the classification. Some of the new potential habitats (e.g. shelf habitats for Azores or "facies" due to biogeography), need to be assessed according to their difference to "mainland" types to decide whether the variation should be accommodated by the expansion of an existing class or creation of new class. The same issue arose for deep-sea habitats based on large fauna, which could be merged into a common set of biotopes. There was no doubt that proposals for new habitat classes should be agreed across scientific communities and added to classification via a suitable higher structure.

\subsubsection{Artificial types}

Concerns were raised also on how to classify or map artificial marine habitats. It is not clear for some scientists if artificial substrata should be classified as artificial habitats (Class J) or assigned to existing "natural" types. This is the case, for example, for established communities (e.g. fucoids on concrete in the intertidal). EUNIS encompasses these within the relevant 'rock/hard substratum' biotope, as the community is similar and working with this assumption would avoid duplicating communities across the classification.

The marine section of EUNIS also has a number of 'fouling' communities (e.g. on wrecks, marine pontoons), which represent more newly-establishing communities (i.e. not climax). It was suggested that expansion of these categories is needed as well as the inclusion of classes for artificial habitats such as reef habitats (e.g. cultivated oyster beds).

\subsubsection{Goods and Services}

It was suggested that information on goods and services provided by the habitat classes should be incorporated into the EUNIS habitat descriptions, as this information can contribute considerably to shaping priorities, assessing management choices and applying marine spatial plans in European seas. Through research carried out by Salomidi et al. (2012), 56 EUNIS Level-4 marine biotopes were reviewed and existing information on the goods and services they provide were compiled (sensu Beaumont et al. (2007)), as well as their sensitivity to major human activities. Evaluation of the selected marine biotopes, based on the relevant literature and expert judgment, yielded $91 \%$ being assessed as highly important in providing at least one basic category of goods and services. The EUNIS database proved to be a useful tool for identifying and assessing natural ecosystem components, providing a well-defined and adequately fine-scaled classification framework. 


\section{Final remarks}

It is scientifically agreed that there are a number of issues unique to the development and implementation of broad-scale classification schemes such as EUNIS, and these were also echoed by colleagues in the USA who are developing and utilizing CMECS (Coastal and Marine Ecological Classification Standard). In the previous sections, the most significant strengths and weaknesses experienced by scientists of different regions in the applicability of EUNIS for marine habitat classification have been highlighted. It was commonly agreed that the structure and underlying assumptions of the current EUNIS classification system requires improvements to make it applicable to all regions, more ecologically-meaningful and to make it useful when producing map outputs. Nevertheless, several opportunities were identified for modifying the system in order to make it more fit-for-purpose for habitat categorization, and consequently, for marine mapping, implementation of European directives (e.g. Habitats Directive, MSFD, INSPIRE, etc.), management purposes and MSP. The suggested critical improvements could be summarised as (i) inclusion of new habitat classes observed in the field, (ii) revision of the existing habitats to enhance the ecological significance of the scheme and its comprehensiveness, (iii) development of EUNIS below level 4, and (iv) development into less well-represented biogeographic areas such as the deep-sea, the Black Sea and the southwestern European seas (with a particular focus on the Atlantic Area region, specifically the Bay of Biscay and the Azores). Some of the previously cited aspects and developments could be based on, or linked to, national habitat typologies developed by some Member States to suit domestic needs.

It was also suggested the need for a process to propose new habitats, and maintain and update the classification. To propose new biotopes a pro forma is needed on the EUNIS website (e.g. http://www.searchmesh.net/default.aspx?page=1864), but it was also suggested that such biotopes should be clearly marked as 'new' (not yet in EUNIS) in any publications/maps.

It was noted the need for a suitable review mechanism of the proposed new habitats, establishing an effective and timely updating mechanism to accommodate new proposals. The development and revision of the classification requires the input from science and policy/managers, and it would be necessary to define the role of national governments as well as scientists in updating the classification to ensure continuity of classification versus the revision based on newly available data. In that sense, a clear mechanism/timing in the process is also needed so that old versions of the classification could be related to new versions. For further development, the ETC-BD should bring forward proposals as soon as possible, establishing an editorial group, a marine subcommittee or a more ad hoc process. Such reviews and development were found to be crucial to the adaptation of the EUNIS hierarchical habitat classification to the European biogeographic regions and to facilitate the mapping of harmonised biotope data across Europe.

\section{Conclusions}

The workshop ended with a final declaration that the EEA and ETC-BD should take account of the concerns raised during the presentations and round table discussion of the workshop "Using EUNIS habitat classification for benthic mapping in European seas" - organized under the framework of the Interreg project MeshAtlantic - in order to identify weaknesses and design a process to further develop the marine component of the EUNIS habitat classification. It was also declared that the European marine 
habitat mapping and classification scientists community are willing to further contribute to its development, supported by necessary resources, with a view to seeking a significant European-wide update by 2014. Hopefully, the workshop results will contribute to the revision and development of the current version of the classification.

\section{Acknowledgements}

This workshop was supported by MeshAtlantic project (Atlantic Area Transnational Cooperation Programme 2007-2013 of the European Regional Development Fund). The Scientific Committee of the workshop was composed by: Ibon Galparsoro (AZTITecnalia; Spain); Jacques Populus (IFREMER; France); Ángel Borja (AZTI-Tecnalia; Spain); Pascale Fossecave (IMA; France); Rosa Freitas (University of Aveiro; Portugal); Jorge Gonçalves (University of Algarve; Portugal); Victor Henriques (IPIMAR; Portugal); Fergal McGrath (Marine Institute; Ireland); José Luis Sanz (IEO; Spain); Patricia da Silva Amorim (University of Azores; Portugal) and Fernando Tempera (University of Azores; Portugal). This paper is contribution number 595 from AZTI-Tecnalia (Marine Research Division).

\section{Bibliography}

Al-Hamdani, Z., J. Reker, 2007. Towards marine landscapes in the Baltic Sea. Geological Survey of Denmark and Greenland, Copenhagen. (BALANCE Interim Report, No. 10). pp.

Beaumont, N. J., M. C. Austen, J. P. Atkins, D. Burdon, S. Degraer, T. P. Dentinho, S. Derous, P. Holm, T. Horton, E. van lerland, 2007. Identification, definition and quantification of goods and services provided by marine biodiversity: Implications for the ecosystem approach. Marine Pollution Bulletin, 54: 253-265.

Bekkby, T., P. E. Isachsen, M. Isaeus, V. Bakkestuen, 2008. GIS modeling of wave exposure at the seabed: A depth-attenuated wave exposure model. Marine Geodesy, 31: 117-127.

Borja, Á., M. Elliott, J. Carstensen, A.-S. Heiskanen, W. van de Bund, 2010. Marine management - Towards an integrated implementation of the European Marine Strategy Framework and the Water Framework Directives. Marine Pollution Bulletin, 60: 2175-2186.

Briggs, J. C., B. W. Bowen, 2012. A realignment of marine biogeographic provinces with particular reference to fish distributions. Journal of Biogeography, 39: 12-30.

Brown, C. J., S. J. Smith, P. Lawton, J. T. Anderson, 2011. Benthic habitat mapping: A review of progress towards improved understanding of the spatial ecology of the seafloor using acoustic techniques. Estuarine, Coastal and Shelf Science, 92: 502520.

Cameron, A., N. Askew, 2011. EUSeaMap - Preparatory Action for development and assessment of a European broad-scale seabed habitat map final report. Available at http://jncc.defra.gov.uk/euseamap. 194 pp.

Coggan, R., C. R. S. Barrio Froján, M. Diesing, J. Aldridge, 2012a. Spatial patterns in gravel habitats and communities in the central and eastern English Channel. Estuarine, Coastal and Shelf Science doi: 10.1016/j.ecss.2012.06.017.

Coggan, R., M. Diesing, 2011. The seabed habitats of the central English Channel: A generation on from Holme and Cabioch, how do their interpretations match-up to modern mapping techniques? Continental Shelf Research, 31: S132-S150.

Coggan, R., M. Diesing, 2012. Rock Ridges in the Central English Channel. Pages 471-480 in P. T. Harris,E. K. Baker, editors. Seafloor Geomorphology as Benthic Habitat. Elsevier, London. 
Coggan, R., B. Pearce, C. James, 2012b. EUNIS: Issues with application to broadscale habitat mapping. Revista de Investigación Marina, 19(2): 55-57. http://www.azti.es/rim/component/content/article/42.html.

Coggan, R. A., J. W. C. James, B. Pearce, P. J., 2011. Using the EUNIS habitat classification system in broadscale regional mapping: some problems and potential solutions from case studies in the English Channel. ICES CM2011/G:03.

Coltman, N., N. Golding, E. Verling, 2008. Developing a broad-scale predictive EUNIS habitat map for the MESH study area. (http://www.searchmesh.net/pdf/MESH\%20EUNIS\%20model.pdf [Accessed: 10/07/2012]. $16 \mathrm{pp}$.

Connor, D. W., J. H. Allen, N. Golding, K. L. Howell, L. M. Lieberknecht, K. O. Northen, J. B. Reker, 2004. Marine Habitat Classification for Britain and Ireland Version 04.05. http://eunis.eea.europa.eu/habitats-factsheet.jsp?idHabitat=441

Council Directive 2007/2/EC of the European Parliament and of the Council of 14 March 2007 establishing an Infrastructure for Spatial Information in the European Community (INSPIRE).

Council of Europe, 2010. Revised annex I of Resolution 4 (1996) of the Bern Convention on endangered natural habitats types using the EUNIS habitat classification. TPVS/PA(2010)10revE, Council of Europe, Strasbourg. https://wcd.coe.int/com.instranet.InstraServlet?command=com.instranet.CmdBlobGet \&Instranet Image $=1763389 \&$ SecMode $=1 \&$ Docld $=1648180$ \&Usage $=2$.

Dauvin, J. C., G. Bellan, D. Bellan-Santini, 2008a. The need for clear and comparable terminology in benthic ecology. Part I. Application of the European Directives. Aquatic Conserv: Mar. Freshw. Ecosyst., 18: 432-445.

Dauvin, J. C., G. Bellan, D. Bellan-Santini, 2008b. The need for clear and comparable terminology in benthic ecology. Part II. Application of the European Directives. Aquatic Conserv: Mar. Freshw. Ecosyst., 18: 446-456.

Davies, C. E., D. Moss, 2002. EUNIS Habitat Classification, February 2002. P. European Topic Centre on Nature Protection and Biodiversity. pp.

Davies, C. E., D. Moss, M. O. Hill, 2004. EUNIS Habitat Classification revised. Report to the European Topic Centre on Nature Protection and Biodiversity, European Environment Agency. October 2004. 310 pp.

http://eunis.eea.europa.eu/upload/EUNIS_2004_report.pdf pp.

Diesing, M., R. Coggan, K. Vanstaen, 2009. Widespread rocky reef occurrence in the central English Channel and the implications for predictive habitat mapping. Estuarine, Coastal and Shelf Science, 83: 647-658.

European Commission, 2008. Roadmap for Maritime Spatial Planning: Achieving Common Principles in the EU. Communication from the Commission. Brussels, 25.11.2008. $\operatorname{COM}(2008) 791$ final. $12 \mathrm{pp}$.

Fabri, M. C., J. Galéron, M. Larour, G. Maudire, 2006. Combining the Biocean database for deep-sea benthic data with the online Ocean Biogeographic Information System. Marine Ecology Progress Series, 316: 215-224.

Folk, R. L., 1974. Petrology of sedimentary rocks, Austin.

Galparsoro, I., Á. Borja, V. Kostylev, I. Legorburu, G. Rodríguez, I. Muxika, P. Liria, M. Pascual, Submitted. Process-driven characterization and benthic soft-bottom habitat modelling, for marine spatial planning and environmental status assessment, within the Basque continental shelf (Bay of Biscay).

Galparsoro, I., Á. Borja, I. Legorburu, C. Hernández, G. Chust, P. Liria, A. Uriarte, 2010. Morphological characteristics of the Basque continental shelf (Bay of Biscay, northern Spain); their implications for Integrated Coastal Zone Management. Geomorphology, 118: 314-329.

Galparsoro, I., Guest Ed., 2012. Using EUNIS Habitat Classification for Benthic Mapping in European Seas. Revista de Investigación Marina, 19(2): 21-70. http://www.azti.es/rim/component/content/article/42.html

Glockzin, M., M. L. Zettler, 2008. Spatial macrozoobenthic distribution patterns in relation to major environmental factors- A case study from the Pomeranian Bay (southern Baltic Sea). Journal of Sea Research, 59: 144-161. 
Guarinello, M. L., E. J. Shumchenia, J. W. King, 2010. Marine Habitat Classification for Ecosystem-Based Management: A Proposed Hierarchical Framework. Environmental Management, 45: 793-806.

Howell, K. L., 2010. A benthic classification system to aid in the implementation of marine protected area networks in the deep/high seas of the NE Atlantic. Biological Conservation, 143: 1041-1056.

Howell, K. L., J. S. Davies, B. E. Narayanaswamy, 2010. Identifying deep-sea megafaunal epibenthic assemblages for use in habitat mapping and marine protected area network design. Journal of the Marine Biological Association of the United Kingdom, 90: 33-68.

ICES, 2011. Annual meeting report of Working Group on Marine Habitat Mapping, http://www.ices.dk/reports/SSGSUE/2011/WGMHM11. (J. Populus ed.).

James, J. W. C., B. Pearce, R. A. Coggan, S. H. L. Arnott, R. Clark, J. F. Plim, J. Pinnion, C. Barrio Frójan, J. P. Gardiner, A. Morando, P. A. Baggaley, G. Scott, N. Bigourdan, 2010. The South Coast Regional Environmental Characterisation. British Geological Survey Open Report OR/09/51. 249 pp.

James, J. W. C., B. Pearce, R. A. Coggan, M. Leivers, R. W. E. Clark, J. F. Plim, J. M. Hill, S. H. L. Arnott, L. Bateson, A. De-Burgh Thomas, P. A. Baggaley, 2011. The MALSF synthesis study in the central and eastern English Channel. British Geological Survey Open Report OR/11/01. 158 pp.

Long, D., 2006. Seabed sediment classification. MESH project document available online at:

http://www.searchmesh.net/PDF/GMHM3_Detailed_explanation_of_seabed_sedimen t_classification.pdf [Accessed: 10/07/2012].

Madden, C., K. Goodin, R. Allee, G. Cicchetti, C. Moses, M. Finkbeiner, D. Bamford, 2009. Coastal and marine ecological classification standard. NOAA and Nature Serv. Available online: http://www.csc.noaa.gov/benthic/cmecs/. 107 pp.

McBreen, F., N. Askew, A. Cameron, D. Connor, H. Ellwood, A. Carter, 2011. UKSeaMap 2010: Predictive mapping of seabed habitats in UK waters. JNCC Report, No. 446. $\mathrm{pp}$.

Pearce, B., J. W. C. James, R. A. Coggan, C. Chambers, J. M. Hill, D. Tappin, 2011. Rationalising seabed sediment classification to promote consistency in biotope classification and improve accuracy in predictive biotope mapping. ICES CM 2011/G:5.

Salomidi, M., S. Katsanevakis, Á. Borja, U. Braeckman, D. Damalas, I. Galparsoro, R. Mifsud, S. Mirto, M. Pascual, C. Pipitone, M. Rabaut, V. Todorova, V. Vassilopoulou, T. V. Fernández, 2012. A ssessment of goods and services, vulnerability, and conservation status of European seabed biotopes: a stepping stone towards ecosystem-based marine spatial management. Mediterranean Marine Science, 13: 49-88.

Spalding, M. D., H. E. Fox, B. S. Halpern, M. A. McManus, J. Molnar, G. R. Allen, N. Davidson, Z. A. Jorge, A. L. Lombana, S. A. Lourie, K. D. Martin, E. McManus, C. A. Recchia, J. Robertson, 2007. Marine ecoregions of the world: A bioregionalization of coastal and shelf areas. Bioscience, 57: 573-583.

Tappin, D. R., B. Pearce, S. Fitch, D. Dove, B. Geary, J. M. Hill, C. Chambers, R. Bates, J. Pinnion, M. Green, J. Gallyot, L. Georgiou, D. Brutto, S. Marzialetti, E. Hopla, E. Ramsay, H. Fielding, 2011. The Humber Regional Environmental Characterisation Marine Aggregate Levy Sustainability Fund (MALSF), British Geological Survey Open Report OR/10/54. 317 pp.

Todd, B. J., V. E. Kostylev, 2011. Surficial geology and benthic habitat of the German Bank seabed, Scotian Shelf, Canada. Continental Shelf Research, 31: S54-S68. 